This is an author produced version of a paper published in Landscape Ecology.

This paper has been peer-reviewed and is proof-corrected, but does not include the journal pagination.

Citation for the published paper:

Ranius, Thomas., Johansson, Victor., Schroeder, Martin., Caruso, Alexandro.

(2015) Relative importance of habitat characteristics at multiple spatial scales for wood-dependent beetles in boreal forest. Landscape Ecology. Volume: 30,

Number: 10, pp 1931-1942.

http://dx.doi.org/10.1007/s10980-015-0221-5.

Access to the published version may require journal subscription.

Published with permission from: Springer. "The final publication is available at Springer via http://dx.doi.org/ 10.1007/s10980-015-0221-5.".

Epsilon Open Archive http://epsilon.slu.se 


\section{Relative importance of habitat characteristics at multiple spatial scales for wood-dependent beetles in boreal forest}

Thomas Ranius, Victor Johansson, Martin Schroeder, Alexandro Caruso

Address to authors (same for all authors):

Department of Ecology, Swedish University of Agricultural Sciences, Box 7044, SE-750 07

Uppsala, Sweden

Corresponding author:

Thomas Ranius

Department of Ecology

Swedish University of Agricultural Sciences (SLU)

Box 7044, SE-750 07 Uppsala, Sweden

Phone: +46-18-672334

E-mail: thomas.ranius@slu.se

Date: 5 May 2015

Number of words: about 5950 


\section{Abstract}

2 Context: Species distributions are influenced by habitat conditions and ecological processes at

3 multiple spatial scales. An understanding of the importance of habitat characteristics at different

4 spatial scales is important when developing biodiversity conservation measures.

5 Objectives: We investigated the effect of habitat characteristics or amount at three spatial scales

6 on the occurrence of saproxylic (= dead wood-dependent) beetles.

7 Methods: Saproxylic beetles were sampled under the bark of dead wood in a managed forest

8 landscape in central Sweden. We modelled the occurrence probability in dead wood items of 44

9 species (all species occurring in $>2 \%$ of the items), based on dead wood item characteristics,

10 forest stand characteristics, and habitat connectivity (i.e. area of potentially suitable forest stands

11 in the surrounding of each stand), using hierarchical Bayesian regression.

12 Results: For the majority of species, dead wood item characteristics (especially tree species and

13 whether standing or downed) were more important than measured stand characteristics and

14 habitat connectivity. Whether the stands were clear-cuts, mature forests, or reserves affected

15 some species, whereas the stand-level amount of dead wood per hectare was not important for

16 any species. Habitat connectivity improved the occurrence models for about a half of the species,

17 but there were both positive and negative relationships, and they were generally weak.

18 Conclusions: Forest management should include creation and retention of a high diversity of

19 dead wood to sustain habitat for all species. In a forest-dominated landscape, the spatial

20 distribution of dead wood is of little importance for common saproxylic beetle species.

21

22 Key words: connectivity; dead wood; hierarchical Bayesian regression; island effect; occurrence

23 patterns; sampling effect; saproxylic beetles; threshold 


\section{Introduction}

25 Species distributions are influenced by habitat conditions and ecological processes at multiple spatial scales (Wiens 1989; Levin 1992). Human modifications of natural systems also occur at

27 several scales, and a big challenge in conservation biology is to identify the appropriate spatial scales at which conservation actions most likely will balance the negative effects of human

29 impacts (Wiens 1989; Saunders et al. 1991). An understanding of the relative importance of key habitat characteristics at different spatial scales is therefore important when developing biodiversity conservation measures in human-modified landscapes.

Commercial logging has turned large regions of the natural boreal forest ecosystem of Europe and North America into forest landscapes dominated by monospecific even-aged stands, where the multi-aged and structurally more diverse natural forest stands are rare and scattered (Esseen et al. 1992; Bergeron et al. 2002). This has raised concerns about how to efficiently extract forest products and still maintain biodiversity. For conservation measures to be applied at

37 the scale where they are most probable to improve persistence of naturally occurring species, knowledge of the relative importance of key habitat characteristics at different spatial scales on

39 species occurrence is needed. However, for forest species such knowledge is generally limited (reviews of epiphytic lichens: Nascimbene et al. 2013, and dead-wood associated species:

41 Sverdrup-Thygeson et al. 2014; see however bird studies, e.g., Saab 1999; Rolstad et al. 2000).

43 dead wood, or on other saproxylic organisms (Stokland et al. 2012). Fungi and beetles are the

44 largest groups among the saproxylic organisms. These organisms have been given much

45 attention in nature conservation, because intensive forest management strongly decreases the 46 quantity and diversity of coarse dead wood (Siitonen 2001). For instance, more than a half of all 
47 red-listed forest species in Fennoscandia are saproxylic. Saproxylic species are often associated

48 with certain characteristics of the dead wood items (e.g. Lindhe et al. 2005; Berglund et al.

49 2011). At the stand scale, a higher amount of dead wood have been found to increase species

50 richness (Lassauce et al. 2011), but its effect on the probability of occurrence of individual

51 species has rarely been studied. Since forest habitats are dynamic, species occurrence relies on

52 colonisation from dispersal sources in the surrounding landscape (Ranius et al. 2014).

53 Consequently, the composition of the surrounding landscape may influence the occurrence

54 patterns of saproxylic organisms (e.g. Gu et al. 2002; Ranius et al. 2010). Most studies that

55 investigate the effect of variables at various spatial scales on saproxylic organisms in forests

56 have, however, either ignored the importance of habitat connectivity (Stenbacka et al. 2010;

57 Berglund et al. 2011) or focused on single species (e.g. Sverdrup-Thygeson and Midtgaard 1998;

58 Schroeder et al. 2007; Jackson et al. 2012; Rubene et al. 2014). Therefore, more knowledge is

59 needed on the relative importance of dead wood quality, stand characteristics, and surrounding

60 landscape on a larger range of saproxylic species.

Hierarchical Bayesian modelling could be used for fitting species distribution models with

62 complex multilevel structures to properly model the influence of different explanatory variables

63 at their hierarchical level and account for different sources of variation across different spatial

64 scales (Gelman and Hill 2007). Recently, such approaches have been used for quantifying habitat

65 requirements of individual species in whole communities, based on the relative influence of local

66 and larger-scale explanatory variables. Such analyses have been done on saproxylic fungi

67 (Berglund et al. 2011; Nordén et al. 2013) but to our knowledge not on any other forest-dwelling

68 groups. 
The aim of this study was to investigate the relative importance of habitat characteristics at

70

71

72

73

74

75

76

\section{Methods}

78

79

80

81

82

83

84

85

86

87

88

89

90

multiple spatial scales for explaining the occurrence of saproxylic beetles. Specifically, we

modelled the occurrence probability of individual beetle species on dead wood items, based on

characteristics of dead wood items, stand characteristics, and habitat connectivity, using the

hierarchical Bayesian framework. To evaluate the relative importance of spatial scale, we

compared average differences in deviance information criterion (DIC) between models that included different sets of variables.

\section{Study landscape and stand selection}

The study was conducted in a 20000 ha study landscape (Fig. 1) in the Swedish province of Hälsingland (Fig. 1; $62^{\circ} \mathrm{N}, 16^{\circ} \mathrm{E}$ ), situated in the southern boreal vegetation zone (Sjörs 1999).

Data on dead wood amounts are available from this landscape (Ekbom et al. 2006). The forest land in the study landscape is owned by one forest company, Holmen Skog AB. Since the 1950's, the forest has been managed more intensively and harvested at thinnings and by clear-felling. Therefore, the landscape is today mainly composed of even-aged management blocks (stands) covering the entire rotation period of about 100 years. There are also three large, legally protected nature reserves, covering 3.1\% of the landscape. Norway spruce (Picea abies (L.) Karsten) and Scots pine (Pinus sylvestris L.) dominate the forests, followed by birch (Betula pendula Roth and B. pubescens Ehrh.) and aspen (Populus tremula L.). Productive forest (i.e. with a potential forest growth $>1 \mathrm{~m}^{3} \mathrm{ha}^{-1}$ ) covers $83.0 \%$ of the landscape. In the managed stands, deciduous trees rarely constitute $>20 \%$ of the standing volume. 
We surveyed beetles in 56 forest stands, which all were productive forests dominated by

92 Scots pine or Norway spruce. We used databases from the forest owner to randomly select these

93 stands, interspersed across the study landscape and classified into three stand types (Table 1). 1)

94 “Clear-cuts" were 3-7 years old canopy-open stands; 2) "mature" stands ( $\geq 60$ years old) were

95 canopy-closed, managed stands; and 3) “reserves” were canopy-closed, unmanaged forests that

96 are legally protected. These three stand types are potentially important habitat for saproxylic

97 beetles living under bark, since they are characterized by large volumes of dead wood with bark,

98 compared to managed stands 8 - 59 years old, where the dead wood recruitment is low and most

99 of the remaining dead wood items have lost their bark (Ekbom et al. 2006). Due to large sizes of

100 the included three reserves (427, 242, and 82 ha), we divided them into 6, 6, and 2 equally sized

101 sub-areas, respectively. The sub-areas were treated as individual stands in the analyses, and this

102 treatment was supported by low levels of spatial autocorrelation of the residuals from the best

103 full models (see Statistical analyses) for all species tested (Moran’s I, $\mathrm{p}_{\min }=0.07$ ). More mature

104 stands were surveyed than clear-cuts (27 vs. 15), which reflects the difference in total area

105 between these two stand types in the study landscape.

106

107 Beetle sampling

108 We aimed at sampling saproxylic beetles in 10 dead wood items per forest stand. We only 109 selected items with a diameter $>10 \mathrm{~cm}$ and a length $>0.5 \mathrm{~m}$ with bark left, but avoided the 110 youngest decay stage in which bark beetles are typically dominating. In each forest stand, the 111 selection was done randomly from logs (downed CWD) and snags (standing CWD) that occurred 112 within one of four $20 \mathrm{~m} \times 100 \mathrm{~m}$ sampling rectangles. If fewer than 10 dead wood items were 113 found in this way, we searched in the remaining parts of the stand for suitable dead wood items. 
114 If there still were fewer than 10 available items, we sampled all available items. During two 115 years (2002 and 2003), 383 dead wood items were sampled. For each item we sieved $1 \mathrm{~m}^{2}$ of 116 bark through a coarse net (Wikars et al. 2005), and the resulting fine fraction was placed into

117 Tullgren funnels (30 cm wide, $8 \mathrm{~mm}$ mesh size) where beetles were extracted under a lamp

118 (Southwood and Henderson 2000). We used $60 \mathrm{~W}$ light bulbs as heat and light source, and

119 extraction lasted for at least $24 \mathrm{~h}$. We identified all adult Coleoptera to species or genus level, but

120 in the analyses we only included species known to be obligate saproxylic (Dahlberg and

121 Stokland 2004). Nomenclature of beetles follows Silfverberg (2004).

122

123 Explanatory variables

124 We measured variables that may affect the occurrence of saproxylic beetles on three spatial 125 scales: dead wood items, stands, and surrounding landscape. For each dead wood item we 126 recorded five explanatory variables: diameter, tree species, position (standing or downed), degree 127 of shade, and decay stage. We estimated the degree of shade on a four-level scale: exposed to 128 direct sunlight during 1) $>75 \%$, 2) 50-75\%, 3) $25-50 \%$, and 4) < 25\% of the day. The decay 129 stage was estimated on a six-level scale based on the hardness of the wood (Siitonen and Saaristo 130 2000).

131 We analysed three stand variables: stand size, amount of coarse dead wood, and stand type. 132 We obtained stand size using databases from the forest owner, and amount of coarse dead wood 133 (both logs and snags) from a previous study in the same forest stands (Ekbom et al. 2006). For 134 coarse dead wood amount, we used volume $\left(\mathrm{m}^{3}\right)$ dead wood $\cdot \mathrm{ha}^{-1}$, including dead wood items 135 with a diameter $>10 \mathrm{~cm}$ (7 cm for deciduous trees) and a length $>0.5 \mathrm{~m}$. We included stand type 
136 because clear-cuts, mature stands, and reserves differ from each other regarding, e.g., forest age 137 and exposure to sun and wind (Table 1).

138 At the landscape scale, we estimated the amount of habitat in the surrounding landscape by 139 summing the area of all stand types defined as habitat (i.e. clear-cuts, mature stands, and 140 reserves, since they have larger volumes of dead wood with bark; Ekbom et al. 2006) within four 141 buffer circles (500, 1000, 2000, and $4000 \mathrm{~m}$ radius, respectively) around each target stand. We 142 used a measure based only on habitat availability since that could potentially be used in forest 143 planning, whereas connectivity measures that require data about individual species' occurrence 144 patterns and biology are not feasible in most landscapes due to lack of information. We used a 145 buffer metric, since for saproxylic beetles it performs equally well as measures that up-weight 146 closer patches (Ranius et al. 2010). The estimation of surrounding habitat amount was done in 147 ArcMAP 10, and the maximum radius (4000 m) was the maximum distance for which we had 148 available information of stand characteristics for all surrounding stands. Six of the analysed 149 species were identified as canopy-closed species, since they either did not occur in clear-cuts or 150 were associated with closed stands according to statistical analyses (i.e. negative 95\% credible 151 intervals for clear-cut did not overlap 0; Fig. 2). For these six species, we used the summed area 152 of only mature stands and reserves as the habitat connectivity variable. In the analyses, we tested 153 the four spatial scales (radii) for the habitat connectivity one by one in separate models. For 154 stands situated spatially close, the buffer circles overlapped, and we hence to some extent psedo155 replicate the connectivity measure. However, that is a minor problem as the spatial 156 autocorrelation was low for the model residuals (see Study landscape and stand selection). We checked all continuous explanatory variables for cross-correlations prior to the 158 analyses. The highest Pearson correlation coefficient, $r=0.3$, was found between stand size and 
159 dead wood amount $\cdot$ ha $^{-1}$. For tests of associations between categorical and continuous variables, 160 we performed one-way ANOVA’s with Tukey’s Honestly Significant Differences post-hoc test.

161 Reserve stands were larger than both clear-cuts and mature stands, and their dead wood amounts

$162 \cdot$ ha $^{-1}$ were also higher (Table 1). Individual dead wood items were less shaded in clear-cuts

163 compared to both mature stands and reserves, and more shaded in mature stands than in reserves

164 (Table 1). Dead wood diameter was greater in clear-cuts compared to both mature stands and 165 reserves (Table 1$)$.

166

167 Statistical analyses

168 We modelled occurrence probability of individual beetle species based on dead wood 169 characteristics, stand characteristics, and habitat connectivity, while accounting for the 170 hierarchical structure of the data. Analyses were conducted for the most frequent 44 species, 171 which had occurrences in at least eight (> 2\%) of the sampled dead wood items. Specifically, we 172 analysed the probability of occurrence on individual dead wood items, using Bayesian

173 hierarchical generalized linear models (Gelman and Hill 2007) with a logit link function (logistic 174 regression) and varying intercepts. The hierarchical Bayesian framework enables the utilization 175 of explanatory variables measured at the stand level (i.e. at the higher hierarchical level), as they 176 are used to model the stand-specific intercepts (Gelman and Hill 2007). We assumed a Bernoulli 177 probability distribution of the binary response variable ( $\mathrm{y}_{\mathrm{ij}}$; species presence/absence) and 178 modelled species occurrence probability on dead wood item $i$ in stand $j$, i.e. $\mathrm{P}\left(\mathrm{y}_{\mathrm{ij}}=1\right)$ as:

$$
\operatorname{logit}\left(P\left(y_{i j}=1\right)\right)=\alpha_{j}+\sum_{k=1}^{n} \beta_{k} X_{i j k}
$$


180 where $\alpha_{j}$ is the stand-specific intercept (see below), $X_{i j k}$ is the dead wood item-level explanatory

181 variable $k$ for dead wood item $i$ in stand $j$ and $\beta_{\mathrm{k}}$ is the dead wood item-level effect-size

182 parameter of explanatory variable $k$ ( $n$ in total). The stand-specific intercepts $\left(\alpha_{j}\right)$ were modelled 183 as:

$$
\alpha_{j} \sim N\left(\mu_{\alpha_{j}}, \sigma_{\alpha}\right)
$$

184 where $\sigma_{\alpha}$ is the standard deviation of a normal distribution with a mean $\left(\mu_{\alpha j}\right)$ modelled based on 185 the stand-level explanatory variables as:

$$
\mu_{\alpha_{j}}=\gamma+\sum_{m=1}^{h} \rho_{m} Z_{j m}
$$

186

187 where $\gamma$ is an intercept parameter, $Z_{j m}$ is the stand-level explanatory variable $m$ for stand $j$ and $\rho_{\mathrm{m}}$ 188 the associated effect-size parameter ( $h$ in total). Hence, the intercepts vary between stands and $\sigma_{\alpha}$ 189 determines the between-stand variation (here called random error). The landscape-scale variable 190 (habitat connectivity at four spatial scales) was treated as a stand variable in the model, but was 191 added separately at the end of the model-building procedure. We constructed hierarchical Bayesian models for each species using different sets of 193 variables, but always with a hierarchical structure (i.e. with varying intercepts). First, we 194 parameterized one model containing only dead wood variables (henceforth, dead wood model). 195 Then we selected the model with the lowest DIC (deviance information criterion) among models 196 with all combinations of the five dead wood variables. DIC is analogous to the Akaike 197 information criterion (AIC), and is well-suited for Bayesian hierarchical modelling 198 (Spiegelhalter et al. 2002). Second, we repeated the same model selection procedure, but with 199 only stand variables included (henceforth, stand model). Third, we constructed full models with 
200 both dead wood and stand variables included in the model selection procedure. The variables

201 included in these full models could be only dead wood, only stand, both dead wood and stand, or

202 no variables, depending on the species tested. To evaluate the relative importance of dead wood

203 and stand variables, we compared the average differences in DIC between the hierarchical null

204 model (i.e. including stand identity as a random factor but no explanatory variables) and the dead

205 wood, stand, and full model, respectively. Finally, we tested whether adding habitat connectivity

206 at four spatial scales, one by one, to the full models improved the models by reducing DIC.

We estimated the posterior distributions of the Bayesian model parameters in equations (1)

208 and (2), using two Monte Carlo Markov chains of 610000 iterations each. We discarded 10000

209 iterations as 'burn-in' and then saved every 60th iteration to accumulate 10000 values from each

210 chain (i.e. 20000 in total). To improve convergence of the chains and simplify the interpretation

211 of the models, we centred all variables (i.e. subtracted the mean from each measured value) and

212 also standardized (i.e. dividing each measured value by $2 \cdot$ sd) the continuous variables (Gelman

213 and Hill 2007). For categorical dead wood (tree species and position) and stand (stand type)

214 variables, we excluded categories in which the species was not found. Consequently, we

215 excluded birch for seven species, clear-cuts for three species, and both birch and clear-cuts for

216 one species (Table A1).

217 We used uninformative prior distributions for all model parameters. We used normal

218 distributions with mean $=0$ and variance $=1000$ for all effect size parameters and the intercept $\gamma$,

219 while $\sigma_{\alpha}$ was drawn from a uniform distribution between 0 and 100. To evaluate convergence,

220 we visually inspected the trace plots and used the Gelman-Rubin diagnostic (Gelman and Hill

221 2007). Convergence $(\mathrm{R}<0.1)$ was reached for all estimated parameters. We summarized the

222 posterior distribution of estimated parameters by calculating the distribution mode and Bayesian 
$22350 \%$ and $95 \%$ credible intervals. For the analyses, we used the statistics software JAGS

224 (Plummer 2003) and R 2.14.0 (R Development Core Team 2011).

\section{Results}

227 Characteristics of dead wood items were more important for explaining species' occurrence 228 probability than characteristics measured of the forest stands, as judged by the average reduction 229 in DIC between the hierarchical null models and the dead wood (16.7) and stand (1.7) models, 230 respectively (Fig. 3). When adding habitat connectivity, DIC was reduced by 1.9. The average 231 reduction in DIC between the hierarchical null models and the full models was close to the 232 average reduction between the hierarchical null models and the dead wood models (Fig. 3).

Tree species and position (i.e. standing or downed) were the variables that were important

234 for the largest number of species; they were included in the final occurrence models for 22 and

23521 beetle species, respectively (Fig. 2). However, among the studied species there were no 236 specialists; none occurred only in one tree species or only in either standing or downed dead 237 wood. The majority of the beetles affected by tree species (18 of 21) were associated with 238 conifers (spruce or pine), whereas only three species were associated with birch (i.e. the negative 239 95\% credible intervals for both spruce and pine did not overlap 0; Fig. 2). Furthermore, there 240 were eight species that did not occur on birch at all, and consequently the effect of birch was not 241 tested for them (Table A1). Degree of shade, diameter, and decay stage were included in the full 242 models for 13, 10, and 9 species, respectively (Fig. 2).

243 Stand type was the most important stand characteristic for explaining species occurrence, 244 and was included in the final model for seven species. Clear-cuts had a negative effect on several 245 species: four species did not occur on clear-cuts at all (Table A1), and the occurrence probability 
246 of two species was lower on clear-cuts compared to reserves (Fig. 2). One species was associated

247 with reserves, whereas for two species the occurrence probability was higher in mature stands

248 compared to reserves (Fig. 2). Stand size affected very few species, whereas the amount of dead

249 wood did not affect any of the species.

250 Adding habitat connectivity to the full model improved the models for 24 species, but in

251 most cases the 95\% credible interval included 0 (Fig. 2). For 11 species the relationship was

252 positive, whereas for 13 species it was negative.

253

254 Discussion

255 Relative importance of spatial scales

256 We found that characteristics of the dead wood items were more important than characteristics

257 measured of the forest stand and surrounding landscape for explaining the occurrence of

258 relatively common saproxylic beetles in a managed boreal forest landscape (Fig. 3). Thus, this

259 beetle community are mainly conforming to what in metacommunity ecology is referred to as the

260 species sorting view, which is defined by the close link between species distributions and local

261 conditions (acting directly or by altering competitive abilities) together with sufficient

262 availability of dispersal sources (Leibold et al. 2004). However, our result may not only be a

263 consequence of the species’ biology, but may also reflect that it is easier to measure

264 characteristics relevant for saproxylic species at a dead wood item scale rather than at a stand and

265 landscape scale. The characteristics we used are representative for what is typically measured in

266 biodiversity monitoring and surveys. For that reason our outcome is still relevant for

267 management and conservation, suggesting that strategies should be based more on characteristics

268 of dead wood items rather than stand and landscape characteristics. It should be noted that this 
269 study only includes the 44 relatively common saproxylic species, and for rarer and more

270 specialised species, for which the habitat is more fragmented, habitat connectivity is expected to

271 be more important (Fahrig 1998; Nordén et al. 2013).

272 There were correlations between some characteristics of the dead wood items and stand type

273 (Table 1); however, we believe that these correlations have minor influence on our main

274 conclusions since the characteristics that influenced the largest number of species (tree species

275 and position) did not differ between different stand types. Perhaps stand characteristics would

276 have an overall slightly higher relative importance if shade and diameter was not included at the

277 lower hierarchical level.

278

279 Effects of characteristics of dead wood items

280 The characteristics of dead wood items were important for explaining occurrence of the majority

281 of the saproxylic beetles (Fig. 2). This agrees with earlier studies of saproxylic beetles (Ulyshen

282 and Hanula 2009; Jackson et al. 2012; see however Wikars 2002) and fungi (Stokland and

283 Kauserud 2004; Berglund et al. 2011). For both beetle larvae and fungi, development takes place

284 in one single dead wood item, which can explain why the conditions in individual logs are

285 important for the recruitment of adult beetles and fruiting bodies of fungi. The most important

286 characteristics of the dead wood items for explaining species occurrence in the present study

287 were tree species, position, decay stage, and degree of shade. Even though there were no true

288 specialists, many species occurred more frequently in certain types of dead wood. These dead

289 wood characteristics may reflect microclimatic conditions (moisture and temperature) as well as

290 nutrient supply (for instance, availability of fungi), and have been shown important for

291 explaining occurrence of saproxylic organisms also in earlier studies (e.g. Ranius and Jansson 
292 2000; Jonsell and Weslien 2003; Lindhe et al. 2005; Saint-Germain et al. 2007; Berglund et al.

293 2011). The direction of the impact of dead wood characteristics varied among species, which

294 suggests that a high heterogeneity of microhabitats may increase the diversity of saproxylic

295 species (Davies et al. 2008).

296

\section{Effects of stand characteristics}

298 Even if dead wood characteristics explained most of the variation in the occurrence patterns (Fig.

299 3) also stand characteristics were important; for instance, stand type influenced the occurrence

300 probability of $20 \%$ of the species. This was mainly because species occurred in lower frequency

301 on clear-cuts compared to the canopy-closed mature and reserve stands. This agrees with earlier

302 findings of similarities in saproxylic beetle communities among mature managed and old-growth

303 boreal stands, but divergent species composition in clear-cuts (McGeoch et al. 2007; Stenbacka

304 et al. 2010; Hjältén et al. 2012). One reason for this divergence is the difference in sun exposure,

305 which affects saproxylic beetles (Similä et al. 2002; Lindhe et al. 2005). Species dependent on

306 forest cover continuity, dead wood, and large trees have been found to be more species rich in

307 unmanaged forests than in managed ones (Paillet et al. 2010). The relatively weak effect of

308 management in our study may be due to that there are relatively small differences in dead wood

309 amounts between mature managed stands and reserves (Table 1) compared to the differences that

310 often occur between old-growth forests and forests that have been managed by clear-felling since

311 a long time (Siitonen 2001).

312 We found no effect of dead wood amount per hectare and only a weak effect of stand size

313 on species occurrence probability per dead wood item. In many studies, higher amounts of dead

314 wood increase species richness and probability of occurrence of saproxylic organisms per forest 
315

316

317

318

319

320

321

322

323

324

325

326

327

328

329

330

331

332

333

334

335

336

337

stand (Lassauce et al. 2011 and references therein). The positive effects of the amount of dead wood on species richness reported in the literature could in most cases be explained by a sampling effect alone, i.e. by the fact that a larger amounts of dead wood will contain more individuals and this will imply more species (Fahrig 2013). This is the case when window traps are used to collect saproxylic beetles, since they capture beetles from a larger volume of dead wood if situated at a spot with a higher density of dead wood. Our study is one of a few in which the amount of dead wood sampled was standardized, which is necessary when disentangling the island effect (i.e. higher species densities on larger habitat islands) and the sampling effect (Fahrig 2013). For saproxylic beetles, such standardized samples are obtained by searching through certain amounts of dead wood (using, for instance, bark sieving and extraction as in the present study) and when using emergence traps (e.g., Wikars et al. 2005). An island effect is expected according to the island biogeography theory (predictions about species richness;

MacArthur and Wilson 1967) and the resource concentration hypothesis (predictions about population densities; Root 1973). Our results imply that there is no island effect; however, other studies of saproxylic beetles have revealed an island effect, since they have observed a positive effect of habitat amount at the stand scale on the probability of species occurrence per dead wood item (Komonen et al. 2000; Ranius 2002; Sahlin and Schroeder 2010; Victorsson and Jonsell 2013). These studies have mainly focused on species specialised to certain dead wood types with a highly fragmented distribution, while in the present study we analysed the 44 most frequently occurring species in a wide range of dead wood types. Also, a study conducted in the same area as the present study, focusing on certain redlisted saproxylic beetle species, suggested that some species are demanding regarding amounts of certain qualities of dead wood at a local scale (Rubene et al. 2014), but these species were too rare to be analysed in the present study. The lack 
338 of relationship in the present study may be explained by the fact that forest stands with at least

339 some dead wood present occurred relatively continuously in the landscape. Consequently, there

340 are many dispersal sources for the relatively common species that were included in the present

341 study. This makes the amount of dispersal sources within each forest stand a less critical factor.

342 Another possible reasons for the weak effect of current dead wood amounts is that saproxylic

343 species richness may be better explained by other factors which are difficult to measure, such as

344 the historical continuity of dead wood. Some studied indicates that historical continuity is

345 important for rare and threatened saproxylic beetles (Nilsson and Baranowski 1997; Siitonen and

346 Saaristo 2000), but little is known about its effect on more common species. It should also be

347 remembered that in the present study, stand size and dead wood amounts differed between the

348 three stand types, and the weak effect could therefore also be because including stand type in the

349 model removes some of the variation in these two explanatory variables. However, this potential

350 bias is still only valid for a few species; only six species had any stand characteristics that did not

351 overlap zero in their final model.

352

353 Effects of habitat connectivity

354 Habitat connectivity affected the occurrence of many species; however, the effect was usually 355 weak and there were nearly as many negative as positive relationships (Fig. 2). The occurrence 356 of both negative and positive effects suggests that the spatial location of the dead wood items had 357 some effect on species' occurrence; however, the spatial pattern was not clearly associated with 358 habitat density. We had expected a clearer positive relationship, due to higher colonization rates 359 when there are higher habitat density, and thus larger dispersal sources nearby (Thomas et al. 360 1992). One reason could be that we mainly analyse rather common species. Several other studies 
361 of saproxylic beetles, which have shown clearer positive effect of habitat connectivity, have

362 focused on species specialised to habitats that are more fragmented in comparison to the present

363 study (Økland et al. 1996; Ranius et al. 2010; 2014; Götmark et al. 2011; Bergman et al. 2012).

364 It could be that since all species in our study occur in managed forest, and the study landscape is

365 dominated by managed forest, the landscape is not very fragmented for these species. At such

366 low level of habitat fragmentation, habitat quality has generally a greater influence than habitat

367 connectivity on species occurrence patterns (Fahrig 1998; Andrén 1999). Among saproxylic

368 fungi, specialised species have indeed been found to be more sensitive to habitat fragmentation

369 than generalistic species since they respond more negatively to connectivity (Nordén et al. 2013).

370 Another reason for the weak effect in the present study could be that the importance of habitat

371 connectivity may be underestimated when analysing snapshot data in landscapes where habitat

372 conditions change over time (Hodgson et al. 2009). In our study landscape, the area covered by

373 older forest has clearly decreased during the last 50 years, and therefore the current species

374 occurrence patterns may to some extent reflect historical habitat connectivity (Schroeder et al.

375 2007). Thirdly, we measured connectivity as the amount of habitat in the surroundings, while a

376 measure that includes information on habitat quality or species' occurrences would reflect the

377 amount of dispersal sources better (Ranius et al. 2010). An advantage with the measure we used

378 is that it better reflects what could potentially be used in management, since it only requires data 379 that are widely available.

\section{Implications for conservation}

382 We found that for the occurrence of the more common saproxylic beetle species', the quality of

383 dead wood items is more important than their spatial location. The habitat requirements 
384 regarding dead wood characteristics (i.e. tree species, position, decay stage and degree of shade) 385 differed among species. Therefore, conservation measures aiming at mitigating negative impacts 386 of forestry should aim at creating not only large amounts, but also a high diversity of dead wood. 387 Attempts have been made to identify "thresholds" in the dead wood amounts that should be 388 exceeded for sustaining biodiversity (Müller and Bütler 2010). However, due to the lack of 389 relationships between amount of dead wood per stand and probability of occurrence per dead 390 wood item, our study does not lend support for any such thresholds at a forest stand level. Our 391 study only included more common species, but it may be that rarer species is more demanding 392 (cf. Pentillä et al. 2004). To some extent, our outcome may also be because we lack detailed data 393 on the amount of dead wood that is suitable for each species. In that sense our study is more 394 similar to the situation for practitioners, who do not have detailed data about all individual 395 species' occurrence patterns and biology. In our study landscape, the amount of dead wood with 396 certain qualities is probably a key factor to allow persistence of the saproxylic fauna. However, 397 in forest habitats that are more fragmented and for rare and demanding species, high 398 concentration of habitat may be important for species' occurrence (e.g. Ranius et al. 2010;

399 Bergman et al. 2012). 


\section{Acknowledgements}

402 We thank Holmen Skog for access to their databases. Matilda Apelqvist, Björn Forsberg, Markus

403 Franzén, David Isaksson, Niklas Jönsson, Mats Larsson, Per Larsson, Carola Orrmalm, Erik

404 Sahlin, Måns Svensson, and Jan ten Hoopen helped with field and laboratory work. Stig

405 Lundberg identified the beetles. Håkan Berglund, Matthew Hiron, Joakim Hjältén, and Tobias

406 Jeppsson provided valuable comments on the manuscript. The study was supported by the Mistra

407 research program Future Forests (to TR).

408 
409 Table 1. Characteristics (mean and standard error) of the sampled dead wood items and stand 410 types.

\begin{tabular}{|c|c|c|c|c|}
\hline & \multicolumn{3}{|c|}{ Stand type } & \multirow[t]{2}{*}{$\operatorname{ANOVA}(\mathrm{df}=2)^{*}$} \\
\hline & $\begin{array}{l}\text { Clear-cut } \\
(\mathrm{n}=15)\end{array}$ & $\begin{array}{l}\text { Mature } \\
(\mathrm{n}=27)\end{array}$ & $\begin{array}{l}\text { Reserve } \\
(\mathrm{n}=14)\end{array}$ & \\
\hline \multicolumn{5}{|l|}{ Dead wood item characteristics } \\
\hline Birch (\%) & $26.5(6.5)$ & $32.2(5.8)$ & $20.8(4.2)$ & ns \\
\hline Pine (\%) & $24.2(7.5)$ & $29.7(6.5)$ & $43.1(7.7)$ & ns \\
\hline Spruce (\%) & $49.3(8.5)$ & $38.1(6.0)$ & $36.2(7.0)$ & ns \\
\hline Downed (\%) & $39.3(6.9)$ & $45.9(6.2)$ & $37.9(5.5)$ & ns \\
\hline Degree of shade & $1.2(0.1)^{\mathrm{a}}$ & $3.4(0.1)^{\mathrm{b}}$ & $3(0.1)^{c}$ & $F=149.8, p<0.001$ \\
\hline Diameter $(\mathrm{cm})$ & $26.4(2.0)^{\mathrm{a}}$ & $17.6(0.7)^{\mathrm{b}}$ & $20.4(1.0)^{\mathrm{b}}$ & $\mathrm{F}=14.2, \mathrm{p}<0.001$ \\
\hline Decay stage $^{1}$ & $1.2(0.1)$ & $1.2(0.1)$ & $1.2(0.1)$ & ns \\
\hline \multicolumn{5}{|l|}{$\underline{\text { Stand characteristics }}$} \\
\hline Age (year) ${ }^{2}$ & $3(1)$ & $104(7)$ & $>150$ & not tested \\
\hline Size (ha) ${ }^{2}$ & $15(2)^{\mathrm{a}}$ & $12(2)^{\mathrm{a}}$ & $53(4)^{b}$ & $F=72.6, p<0.001$ \\
\hline Dead wood amount $\left(\mathrm{m}^{3} / \mathrm{ha}\right)^{3}$ & $14(3)^{\mathrm{a}}$ & $20(4)^{\mathrm{a}}$ & $34(5)^{b}$ & $F=5.5, p=0.007$ \\
\hline
\end{tabular}

412 type and continuous variables. The p values are adjusted for pairwise comparisons. Different letters $\left({ }^{\mathrm{a}}, \mathrm{b}\right.$, or $\left.^{\mathrm{c}}\right)$ within

413 a row denote significant differences.

$414{ }^{1}$ According to a six-grade scale made by Siitonen and Saaristo (2000), with 0 being the first and 5 the latest stage

$415 \quad{ }^{2}$ According to databases provided by the forest company

$416 \quad{ }^{2}$ Measured as described in Ekbom et al. (2006)

417 
418 Figure 1. Location of the 56 forest stands where beetles were sampled, in a study landscape

419 situated in central Sweden. The distance to the nearest neighbour was, on average, $965 \mathrm{~m}$.

421 Figure 2. Estimates of parameters in Bayesian generalized linear models for occurrence

422 probability of saproxylic beetle species on individual dead wood items. The modes (short vertical

423 lines), 50\% (thick horizontal lines) and 95\% (thin horizontal lines) credible intervals are shown

424 for the full models including or excluding habitat connectivity. Grey lines indicate that the 95\%

425 credible interval includes 0, black lines that it does not. * denotes that parameter estimates are,

426 for visibility reasons, scaled by a factor $10{ }^{1}$ and ${ }^{2}$ denote effects of habitat connectivity at 500

427 and $4000 \mathrm{~m}$, respectively. For the categorical variables “tree species”, “dead wood position”, and

428 "stand type”, only parameters for categories other than the reference category (birch, downed, 429 and reserves, respectively) are given. Dead wood amount was also tested, but that is not shown

430 here since it was not included in the final model for any of the species. Standard deviation of

431 random error $(\sigma)$ is the parameter associated with unexplained between-stand variation.

433 Figure 3. Change in DIC $( \pm \mathrm{SE})$ between models including explanatory variables at different 434 spatial scales and a null model with only the random stand effect included. Variables included in 435 the full models can be only dead wood, only stand, both dead wood and stand, or no variables 436 (see Fig. 2 for species-specific details). hc = habitat connectivity. 


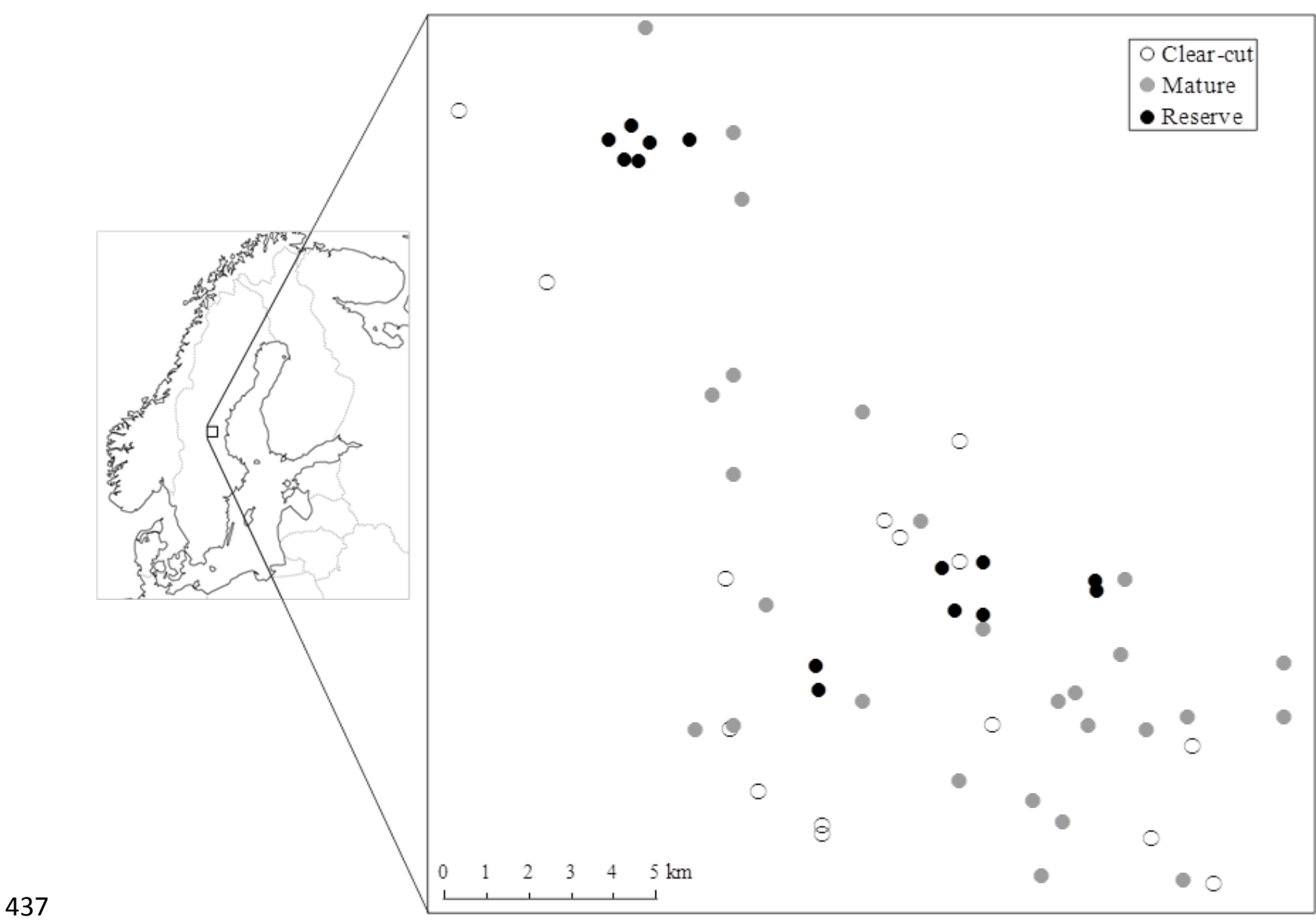

438

$439 \quad$ Fig. 1 


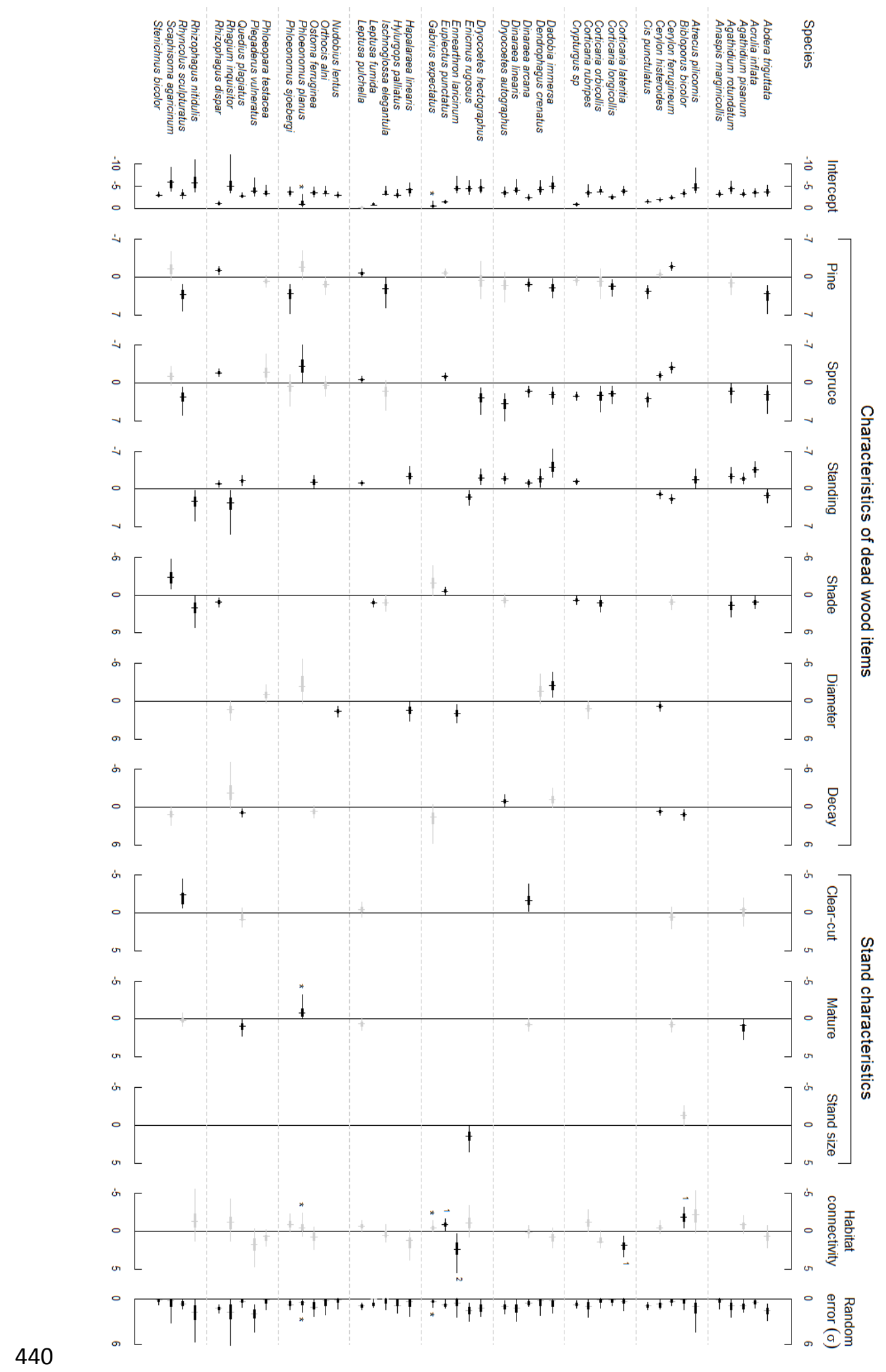

441

Fig. 2 


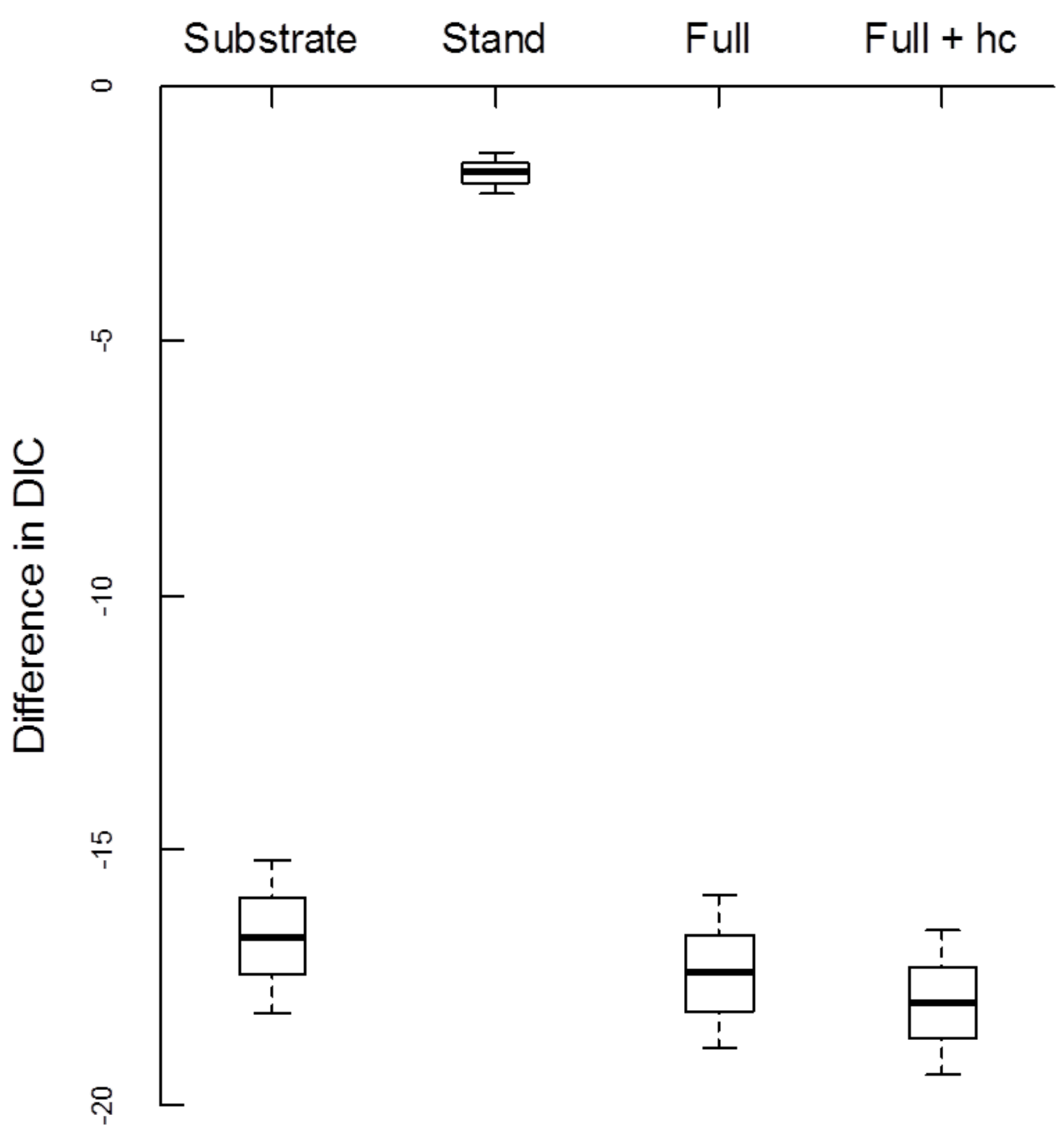

442

443

$444 \quad$ Fig. 3 


\section{References}

Andrén H (1999) Habitat fragmentation, the random sample hypothesis and critical thresholds. Oikos 84:306-308

Bergeron Y, Leduc A, Harvey BD, Gauthier S (2002) Natural fire regime: A guide for sustainable management of the Canadian boreal forest. Silva Fenn 36:81-95

Berglund H, Hottola J, Penttilä R, Siitonen J (2011) Linking substrate and habitat requirements of wood-inhabiting fungi to their regional extinction vulnerability. Ecography 34:864-875

Bergman K-O, Jansson N, Claesson K, Palmer MW, Milberg P (2012) How much and at what scale? Multiscale analyses as decision support for conservation of saproxylic oak beetles. For Ecol Manage 265: 133-141

Dahlberg A, Stokland J (2004) Vedlevande arters krav på substrat - en sammanställning och analys av 3600 arter. Skogsstyrelsen, Jönköping, Sweden

Davies ZG, Tyler C, Stewart GB, Pullin AS (2008) Are current management recommendations for saproxylic invertebrates effective? A systematic review. Biodivers Conserv 17:209-234

Ekbom B, Schroeder LM, Larsson S (2006) Stand specific occurrence of coarse woody debris in a managed boreal forest landscape in central Sweden. For Ecol Manage 221:2-12

Esseen P-A, Ehnström B, Ericson L, Sjöberg K (1992) Boreal forests - The focal habitats of Fennoscandia. In: Hansson L (ed) Ecological principles of nature conservation. Elsevier Science Publishers, Amsterdam., pp 252-325

Fahrig L (1998) When does fragmentation of breeding habitat affect population survival? Ecol Model 105:273-292

Fahrig L (2013) Rethinking patch size and isolation effects: The habitat amount hypothesis. J Biogeography 40:1649-1663 
468 Gelman A, Hill J (2007) Data analysis using regression and multilevel/hierarchical models.

469 Cambridge University Press, Cambridge

470 Götmark F, Åsegård E, Franc N (2011) How we improved a landscape study of species richness

471 of beetles in woodland key habitats, and how model output can be improved. For Ecol

$472 \quad$ Manage 262: 2297-2305

473 Gu W, Heikkilä R, Hanski I (2002) Estimating the consequences of habitat fragmentation on 474 extinction risk in dynamic landscapes. Land Ecol 17:699-710

475 Hjältén J, Stenbacka F, Pettersson RB, Gibb H, Johansson T, Danell K, Ball JP, Hilsczański J

476 (2012) Micro and macro-habitat associations in saproxylic beetles: implications for

477 biodiversity management. PLoS One 7:e41100-e41100

478 Hodgson JA, Moilanen A, Thomas CD (2009) Metapopulation responses to patch connectivity

479 and quality are masked by successional habitat dynamics. Ecology 90:1608-1619

480 Jackson HB, Baum KA, Cronin JT (2012) From logs to landscapes: determining the scale of

481 ecological processes affecting the incidence of a saproxylic beetle. Ecol Entomol 37:233-243

482 Jonsell M, Weslien J (2003) Felled or standing retained wood - it makes a difference for

$483 \quad$ saproxylic beetles. For Ecol Manage 175:425-435

484 Jonsson M (2003) Colonisation ability of the threatened tenebrionid beetle Oplocephala

485 haemorrhoidalis and its common relative Bolitophagus reticulatus. Ecol Entom 28:159-167

486 Komonen A, Penttilä R, Lindgren M, Hanski I (2000) Forest fragementation truncates a food

487 chain based on an old-growth forest bracket fungus. Oikos 90:119-126

488 Lassauce A, Paillet Y, Jactel H, Bouget C (2011) Deadwood as a surrogate for forest

489 biodiversity: Meta-analysis of correlations between deadwood volume and species richness of

$490 \quad$ saproxylic organisms. Ecol Ind 11:1027-1039 
491 Leibold MA, Holyoak M, Mouquet N, Amaresekare P, Chase JM, Hoopes MF, Holt RD, Shurin

492 JB, Law R, Tilman D, Loreau M, Gonzalez A (2004) The metacommunity concept: a

493 framework for multi-scale community ecology. Ecology Letters 7:601-613

494 Levin SA (1992) The problem of pattern and scale in ecology. Ecology 73:1943-1967

495 Lindhe A, Lindelöw Å, Åsenblad N (2005) Saproxylic beetles in standing dead wood density in

496 relation to substrate sun-exposure and diameter. Biodivers Conserv 14:3033-3053

497 MacArthur, RH, Wilson, EO (1967) The theory of island biogeography. Princeton University

$498 \quad$ Press, Princeton, New Jersey, USA. pp. 203

499 McGeoch M, Schroeder M, Ekbom B, Larsson S (2007) Saproxylic beetle diversity in a

500 managed boreal forest: importance of stand characteristics and forestry conservation

$501 \quad$ measures. Div Distrib 13:418-429

502 Müller J, Bütler R (2010) A review of habitat thresholds for dead wood: a baseline for

503 management recommendations in European forests. Eur J Forest Res 129:981-992

504 Nascimbene J, Thor G, Nimis PL (2013) Effects of forest management on epiphytic lichens in

505 temperate deciduous forests of Europe - A review. For Ecol Manage 298:27-38

506 Nilsson SG, Baranowski R (1997) Habitat predictability and the occurrence of wood beetles in

507 old-growth beech forests. Ecography 20:491-498

508 Nordén J, Penttilä R, Siiitonen J, Tomppo E, Ovaskainen O (2013) Specialist species of wood-

509 inhabiting fungi struggle while generalists thrive in fragmented boreal forests. J Ecol 101:701-

$510 \quad 712$

511 Økland B, Bakke A, Hågvar S, Kvamme T (1996) What factors influence the diversity of 512 saproxylic beetles? A multiscaled study from a spruce forest in southern Norway. Biodiver

$513 \quad$ Conserv 5:75-100 
514 Paillet Y, Bergès L, Hjältén J, Ódor P, Avon C, Bernhrdt.Römermann M, Bijlsma R-J, deBruyn

515 L, Fuhr M, Grandin U, Kanka R, Lundin L, Luque S, Magura T, Matesanz S, Mészáros I,

516 Sebastià M-T, Schmidt W, Standvár T, Tóthmérész B, Uotila, A, Valladares F, Vellak K,

517 Virtanen R (2010) Biodiversity differences between managed and unmanaged forests: meta-

518 analysis of species richness in Europe. Conserv Biol 24:101-112

519 Penttilä R, Siitonen J, Kuusinen M (2004) Polypore diversity in managed and old-growth boreal

$520 \quad$ Picea abies forests in southern Finland, Biol Conserv 117:271-283

521 Plummer M (2003) Jags: A program for analysis of Bayesian graphical models using Gibbs

522 sampling. DSC Working Papers. Austrian Association for Statistical Computing, Vienna.

523 R Development Core Team (2011) R: A language and environment for statistical computing. R

524 Foundation for Statistical Computing, Vienna. ISBN 3-900051-07-0

525 Ranius T (2002) Influence of stand size and quality of tree hollows on saproxylic beetles in

$526 \quad$ Sweden. Biol Conserv 103:85-91

527 Ranius T, Jansson N (2000) The influence of forest regrowth, original canopy cover and tree size

528 on saproxylic beetles associated with old oaks. Biol Conserv 95:85-94

529 Ranius T, Johansson V, Fahrig L (2010) A comparison of patch connectivity measures using data

530 on invertebrates in hollow oaks. Ecography 33:971-978

531 Ranius T, Bohman P, Hedgren O, Wikars L-O, Caruso A (2014) Metapopulation dynamics of a

532 beetle species confined to burned forest sites in a managed forest region. Ecography 37: 797-

$533 \quad 804$

534 Rolstad J, Løken B, Rolstad E (2000) Habitat selection as a hierarchical spatial process: The

535 green woodpecker at the northern edge of its distribution range. Oecologia 124: 116-129 
536 Root, RB (1973) Organization of a plant-arthropod association in simple and diverse habitats: the 537 fauna of collards (Brassica oleracea). Ecol Monogr 43: 95-124

538 Rubene D, Wikars L-O, Ranius T (2014) Importance of high quality early-successional habitats 539 in managed forest landscapes to rare beetle species. Biodiv Conserv 23: 449-466

540 Saab V (1999) Importance of spatial scale to habitat use by breeding birds in riparian forests: A $541 \quad$ hierarchical analysis. Ecol Appl 9: 135-151

542 Sahlin E, Schroeder LM (2010) Importance of habitat patch size for occupancy and density of 543 aspen-associated saproxylic beetles. Biodivers Conserv 19:1325-1339

544 Saint-Germain M, Drapeau P, Buddle CM (2007) Host-use patterns of saproxylic phloeophagous 545 and xylophagous Coleoptera adults and larvae along the decay gradient in standing dead black $546 \quad$ spruce and aspen. Ecography 30:737-748

547 Saunders DA, Hobbs RJ, Margules CR (1991) Biological consequences of ecosystem 548 fragmentation - a review. Conserv Biol 5:18-32

549 Schroeder LM, Ranius T, Ekbom B, Larsson S (2007) Spatial occurrence of a habitat-tracking 550 saproylic beetle inhabiting a managed forest landscape. Ecol Appl 17:900-909

551 Siitonen J (2001) Forest management, coarse woody debris and saproxylic organisms:

552 Fennoscandian boreal forests as an example. Ecol Bull 49:11-41

553 Siitonen J, Saaristo L (2000) Habitat requirements and conservation of Pytho kolwensis, a beetle 554 species of old-growth boreal forest. Biol Conserv 94:211-220

555 Silfverberg H (2004) Enumeratio nova Coleopterorum Fennoscandiae, Daniae et Baltiae. $556 \quad$ Sahlbergia 9:1-111 
557 Similä M, Kouki J, Martikainen P, Uotila A (2002) Conservation of beetles in boreal pine 558 forests: the effects of forest age and naturalness on species assemblages. Biol Conserv $559 \quad 106: 19-27$

560 Sjörs H (1999) The background: Geology, climate and zonation. Acta Phytogeographica Suecica 561 84:5-14

562 Southwood TRE, Henderson PA (2000) Ecological methods. Blackwell Science, Oxford 563 Spiegelhalter DJ, Best NJ, Carlin BP, vad der Linde, A (2002) Bayesian measures of model 564 complexity and fit. J R Statist Soc B 64:583-616

565 Stenbacka F, Hjältén J, Hilszczański J, Dynesius M (2010) Saproxylic and non-saproxylic beetle 566 assemblages in boreal spruce forests of different age and forestry intensity. Ecol Appl $567 \quad 20: 2310-2321$

568 Stokland J, Kauserud H (2004) Phellinus nigrolimitatus - A wood-decomposing fungus highly 569 influenced by forestry. For Ecol Manage 187: 333-343

570 Stokland JN, Siitonen J, Jonsson BG (2012) Biodiversity in dead wood. Cambridge University 571 Press, Cambridge

572 Sverdrup-Thygeson A, Midtgaard F (1998) Fungus-infected trees as islands in boreal forest: 573 Spatial distribution of the fungivorous beetle Bolitophagus reticulatus (Coleoptera, 574 Tenebrionidae). Ecoscience 5:486-493

575 Sverdrup-Thygeson A, Gustafsson L, Kouki J (2014) Spatial and temporal scales relevant for 576 conservation of dead-wood associated species: Current status and perspectives. Biodiv

$577 \quad$ Conserv 23:513-535

578 Thomas CD, Thomas JA, Warren MS (1992) Distributions of occupied and vacant butterfly 579 habitats in fragmented landscapes. Oecologia 92:563-567 
580 Ulyshen MD, Hanula JL (2009) Habitat associations of saproxylic beetles in the southeastern 581 United States: A comparison of forest types, tree species and wood postures. For Ecol $582 \quad$ Manage 257:653-664

583 Victorsson J, Jonsell M (2013) Effect of stump extraction on saproxylic beetle diversity in 584 Swedish clear-cuts. Insect Conservation and Diversity 6:483-493

585 Wiens JA (1989) Spatial scaling in ecology. Funct Ecol 3:385-397

586 Wikars LO (2002) Dependence on fire in wood-living insects: An experiment with burned and 587 unburned spruce and birch logs. J Insect Conserv 6:1-12

588 Wikars LO, Sahlin E, Ranius T (2005) A comparison of three methods to estimate species 589 richness of saproxylic beetles (Coleoptera) in logs and high stumps of Norway spruce. Can $590 \quad$ Entomol 137:304-32 